\title{
EL MITO DE ODISEO
}

\section{Miguel Castillo Didier*}

\section{RESUMEN}

Este mito puede considerarse como uno de los más complejos y más cercanos al ser humano de cuantos legó la Antigüedad griega. Humano, porque U lises busca, lucha y sufre porque ama, así como el hombre busca, lucha y sufre porqueama. Complejo, porqueuna multitud de otros personajes, de gran simbolismo, pueblan el escenario de su travesía de retorno al hogar y el terruño. Esos personajes muestran honda humanidad. El viaje de O diseo puede calificarse de "itinerario humano", pues al menos 28 encrucijadas a las que puede verse enfrentado el hombre en su vida son superadas por Odiseo. Además de ser éste un mito complejo, ha demostrado ser abierto, pues ha permitido a muchos escritores aprovechar sus el ementos esenciales o basarse en alguno de ellos. Por nombrar sólo al gunos, se recuerda a Ovidio, Dante, Du Bellay, Tennyson, Joyce, Kazantzakis, Seferis.

Palabras claves: M ito, simbolismo, travesía, hogar.

\section{ABSTRACT}

This myth can be considered as one of the most complex but at the same time closest to human beings of all the myths passed down by ancient Greece. M ost human because Ulysses searched, fought and suffered because heloved, just as man searches, fights and suffers becauseheloves. It is complex because a multitude of other characters, of great symbolism, people the scene of his journey of return to his land and his home. These characters show their deep humanity. His trip can be called a "human itinerary" since at least twenty-eight turning points with which a person is confronted in his or her lifetime are met and overcome by U lysses. As well as being complex, this myth has demonstrated itself to be open since it has permitted many writers to take advantage of its essential elements or has formed a basis for some of them such as Ovid, Dante, Du Bellay, Tennyson, Joyce, Kazantazakis, Seferis.

Keywords: Myth, symbolism, journey, home.

Recibido: 16.05.2003. Aprobado: 09.07.2003.

*Profesor titular en la Facultad deFilosofía y Humanidades dela Universidad de Chiley director del Centro de Estudios Griegos, Bizantinos y Neohelénicos. E-mail: micastil@abello.dic.uchile.cl

Los dos últimos libros que han aparecido son: Grecia y Francisco de M iranda, precursor, héroe y mártir de la independencia hispanoanericana, 2ª ed., Santiago, 2002; y Kavafisíntegro, coedición del Centro con Ediciones Quid, Santiago, 2003. 
Es éste un complejo mundo de personajes: los humanos que aman a O diseo y lo esperan y lo reciben con emoción y alegría; los humanos que lo perjudican y desean perderlo a él y a sus bienes, como los pretendientes, dispuestos incluso a asesinar a su hijo; los personajes extrahumanos que le ponen obstáculos o le tienden trampas y tentaciones. Todo ese mundo es viajado por Ulises, sin perder la voluntad férrea de volver a ver el humo que sube de su casa; de regresar a su tierra y a su hogar. En medio de la cantidad desimbolismos, de personajes, de situaciones y objetos, hay un sentimiento central que se impone y que finalmente se hace realidad: la voluntad de regreso, del nostos, la decisión deU lises de volver a toda costa a su patria y a su casa.

Y conocemos el mito de $O$ diseo a través del poema que narra su viaje. Como la generalidad de los mitos griegos, el de Odiseo llega a nosotros a través de una obra literaria². En su caso, se trata de uno de los dos grandes monumentos que abren para nosotros la literatura y la cultura griegas.

El desarraigo forzado - Ulises tuvo queir a la guerra con Troya-, el dolor por la lejanía de la patria y del hogar y la decisión de regresar, son realidades quehan vivido miles y miles deseres humanos a través delossiglos. Por eso, podemos sentir tan humana la historia deU lises. Pero no sólo esta situación fundamental, sino diversas otras en la vida de un hombre se ven expresadas poéticamente en el mito de $\mathrm{O}$ diseo. Jacinto y Pilar Choza señalan al menos 28 encrucijadas a las que puedeverse enfrentado un hombrey que hallamos en la historia de U lises ${ }^{3}$. Citemos sólo algunas:

- tener que salir de la patria y del hogar,

- tener que estar lejos por largo tiempo,

- no poder regresar, deseándolo vivamente,

- quedar hechizado por una mujer que seduce y sojuzga (Circe),

- recibir la ayuda de una mujer seductora quelo retiene por años (Calipso),

- rechazar una tentación que lo llevaría al desastre (Sirenas),

- superar terribles amenazas de destrucción y muerte (Polifemo, Escila, Caribdis, Simpligades),

- transgredir una prohibición y ser castigado duramente (naufragio por haber abierto el odre de los vientos),

- ser acogido en otro país, en un hogar dulce y benévolo y tener la posibilidad de permanecer allí y no volver a la patria,

- tener durante años el anhelo de volver a la tierra y al hogar y no poder hacerlo,

- perder a la madre mientras se está lejos y sin poder regresar,

2Bermejo, J osé Carlos. Introducción a la sociología del mito griego. M adrid, Akal, 1994, p. 136. 1996. Choza, Jacinto y Choza, Pilar. Ulises, un arquetipo de la existencia humana, Barcelona, Ariel,

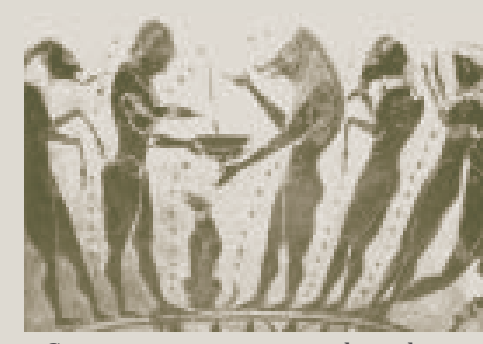

Circe convierte en animales a los compañeros de Ulises. 


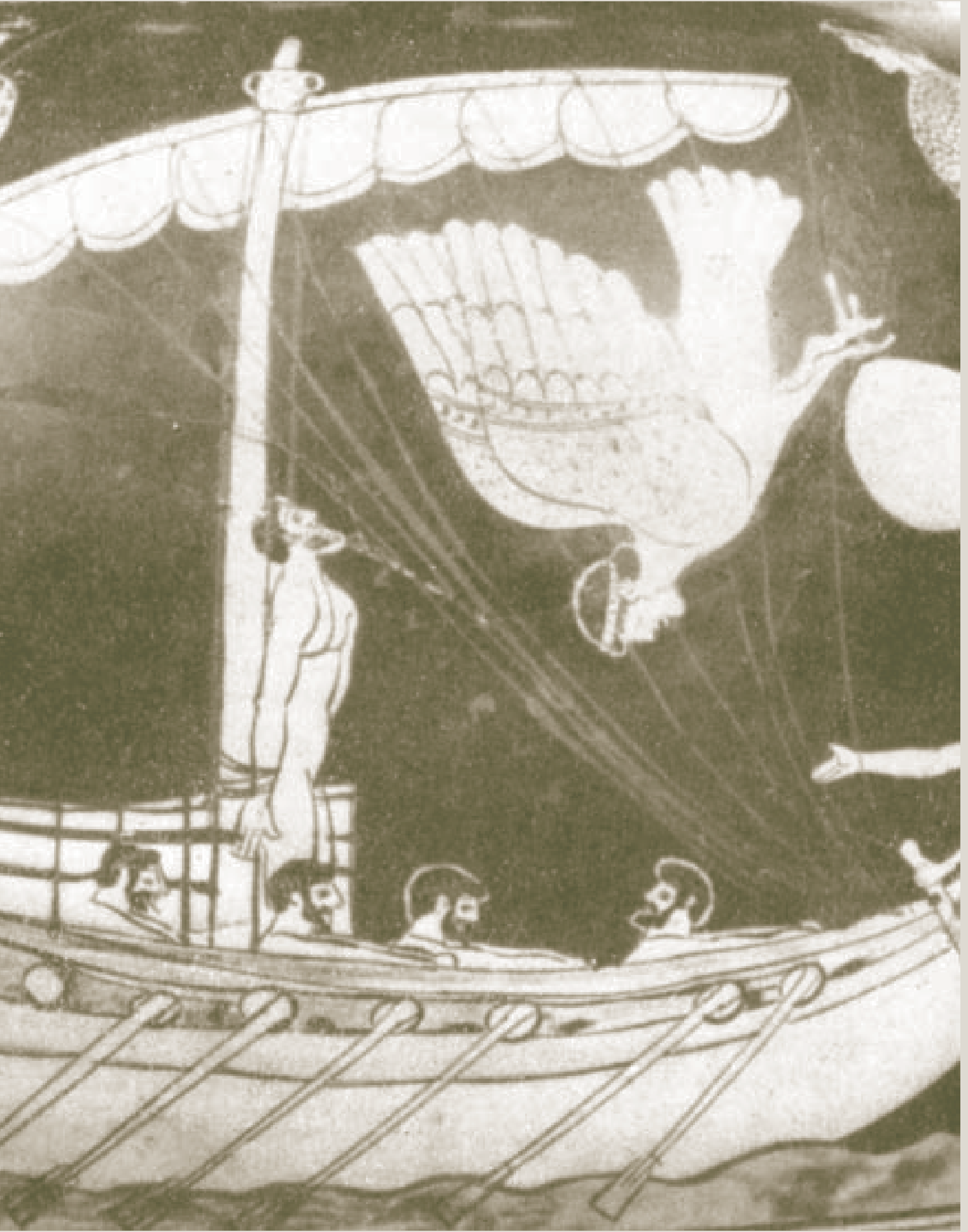

Ulises atado al mástil de su navío resistiendo el canto de las sirenas (vaso griego). 
- vencer innumerables dificultades para poder retornar

- volver a la tierra natal cargado de experiencias y de años.

Y podríamos seguir con esta enumeración.

Así pues, en la formulación del mito de Ulises en la O disea, en palabras dePilar Choza, "parecen estar recogidas, por primera vez y en una secuencia unitaria, las encrucijadas de la existencia humana; los momentos claves en que el hombre se expresa, se delimita, seautointerpreta, secomprende, toma posesión de sí y busca en los demás el reconocimiento de su ser"4.

El O diseo quenos conmueve, el que nos simboliza o nos expresa, es esencialmente el personaje de la O disea. El guerrero de la Ilíada se nos aparece como más lejano y menos humano. En la 0 disea, probado por los padecimientos y peripecias del largo peregrinar, "su persona, cada vez más alejada de los héroes de Troya, se hizo más humana. Sus propios sufrimientos y su resistencia, a pesar de los motivos fantásticos que los provocaron, se volvían más cercanos a la dureza de la vida cotidiana de los hombres corrientes". Así lo destaca Susana Reboreda en su estudio "O diseo: el héroe peculiar" 5 . I dea semejante expresa Lasso de la Vega, explicando así la perdurabilidad del mito odiseano: "Mucho más cercano a nosotros que los héroes de la Ilíada, es Ulises un eterno ideal de Humanidad, uno de los pocos M itos perdurables del espíritu humano. Desde H omero a nuestros días, sin intermisión alguna, la tradición literaria y filosófica universal ha ido descubriendo en él el reflejo de muy diversosideales, con admiración unas veces, con animadversión otras"6. Jorge Guillermo Llosa destaca el hecho de que, además de la "areté" propia del héroe homérico, consistente en la exaltación del propio valer para alcanzar el máximo de gloria, "en el navegante Ulises fulge otro valor ético fundamental en la autenticidad o fidelidad a la propia condición y al destino personal libremente aceptado. Ante todo, su apego a la condición humana"7.

El mito de O diseo, la historia de su viaje narrada por la O disea, se nos aparece como el caminar deun ser humano que, pesea las múltiples peripecias que sufre durante una década, que se agrega a otra década de peligros, en lejanía forzada de su patria, salva su condición de hombre y la lleva a plenitud. Con esta idea, Oscar Gerardo Ramos ha podido calificar a la O disea como "un itinerario humano"8. I tinerario humano, si consideramos al

${ }^{4}$ l bídem, pp. 13-14.

5S. Reboreda: “O diseo, el héroe peculiar", en Bermejo J. C., González R. J. y Reboreda S.: LoS orígenes de la mitología griega, Madrid, A kal, 1996, p. 332.

'Lasso de la Vega, José S.: “U lises y su mundo de ideales éticos”, en "Etica homérica”, Adrados, R. y otros (L. Gil Ed.): Introducción a Homero, Madrid, Ediciones Guadarrama, 1983, p. 315 [Se respetan las mayúsculas del original ].

JJorge G. Llosa: El libro de O diseo, Zig-Zag, 1965, p. 19.

${ }^{8}$ Ramos, O. G.: La Odisea: un itinerario humano, Bogotá, Instituto Caro y Cuervo, 1970. 
hombre como individuo. Pero también si lo consideramos en su aspecto social. Así, para Francisco González García, y lo expresa en su estudio "M ito y epopeya: la historia mítica de Aquiles y la llíada", "lo destacable del personaje de 0 diseo es que éste, a lo largo de los poemas homéricosy, sobretodo, en la O disea, encarna la estabilidad social, la concordia y el buen gobierno" ${ }^{\prime}$.

El mito de 0 diseo, decíamos, es un mito complejo, es como una constelación de mitos. Pero Odiseo mismo, dejando de lado los aspectos de su personalidad que nos muestra la llíada, no parece ser una personalidad especialmente compleja. Es verdad que es caracterizado como el hombre ingenioso, el hombre polytropos, el de los muchos artificios, el de las muchas tretas, como lo muestra su actuar, su enfrentar y vencer las dificultades que halla en su marítima senda. Pero su rasgo esencial es su voluntad de retornar a la patria y al hogar. Sin embargo, acaso por el hecho de que en su peregrinar tuvo tantas y tan variadas experiencias, surgió ya entrelos antiguosla idea de que habría salido una vez más de I taca, atraído por una sirena esta vez irresistible: el afán de nuevas experiencias, de nuevos conocimientos.

Dante, en un sobrecogedor pasaje del "Infierno" de la Divina comedia, pone en boca del propio U lises el relato del nuevo viaje y de su motivación, el afán de aventuras y de conocimientos, afán tan fuerte que logró vencer el amor debido a la fiel Penélope, al padre anciano, al joven vástago, a sus amigos y a su isla:

$\mathrm{Ni}$ las dulzuras de mi hijo, ni la piedad debida a un padre anciano, ni el mutuo amor quedebía hacer dichosa a Penélope, pudieron vencer el ardiente deseo que yo tenía de conocer el mundo, los vicios y las virtudes de los humanos; sino que me lancé por el abierto mar sólo con un navío, con los pocos compañeros que nunca me abandonaron. Vi una y otra costa, hasta España, hasta M arruecos y la isla de sardos y las demás que baña en torno aquel mismo mar... Llegamos a la estrecha embocadura donde Hércules fijó sus límites para que hombre alguno pasase más allá... Oh hermanos míos, les dije, que entre mil peligros habéis llegado a occidente, no neguéis a este breve gozo de vuestro sentido que os resta, el intento de encaminaros hacia el oriente, hacia el mundo deshabitado ${ }^{10}$.

Y así, entre los muchos autores, prosistas y poetas, que han vuelto al personaje mítico y lo han tratado, el antiguo mito toma fundamental mentedos formas. La que en esencia hallamos en la $O$ disea y la que nos entrega $D$ ante. Y así, en el siglo XX, dos inmensas obras nos muestran la vitalidad del mítico personaje: el U lises deJ oyce, en la línea de Homero, y la O disea deKazantzakis ${ }^{11}$,

${ }^{9}$ Bermejo, J. C. y otros. Los orígenes de la mitología griega, cit., p. 279.

${ }^{10}$ Dante. Divina Comedia, "Infierno", Canto XXVI, v. 94 y s.

${ }^{11}$ Un sintético paralelo entre la O disea homérica, la de Kazantzakis y el Ulises de J oyce puede hallarse en nuestro ensayo "El tiempo, la muertey la palabra en la 0 disea de Kazantzakis", Byzantion Nea Hellás, 3-4, 1975, pp. 243-246. 
derivación de la línea de Dante, pero con elementos de sentimientos que expresa U lises en el monólogo homónimo de Tenysson ${ }^{12}$ y otros que el poeta neogriego agrega, para hacer también del nuevo e interminable viaje de O diseo un itinerario humano, pero no de la búsqueda de Itaca-patria-hogar, sino de la Itaca-sentido-de-la-existencia humana, Itaca que finalmente no encuentra, porque no existe.

Se habla del mito como arquetipo, como modelo. Los hombres tenderían a realizar los grandes gestos y movimientos simbólicos configurados por el mito. El mito deO diseo puedequizás ser paradigmático, puedeconstituir un modelo. Pero además, o acaso más que eso, este mito refleja aspectos del alma humana y situaciones que puede vivir el hombrey quemuchos seres humanos han vivido. Odiseo: su amor a la tierra natal y el hogar y su voluntad de volver; Penélope, la fidelidad a toda prueba en el amor y en el recuerdo, y también la prudencia y el recato. Laertes, el amor a la esposa muerta y al hijo ausente; Telémaco: la búsqueda del padre ausente y la fidelidad a su legado; el perro Argos: el amor al amo, expresado con una ternura casi humana. H asta este personaje, el más humilde de todos, nos conmueve por su humanidad. Como anota Gilbert Highet, al Ilegar Odiseo a su hogar, sus parientes necesitan de pruebas para reconocerlo. "Nadie lo reconoce en su hogar [sin necesidad de una sema, de una prueba], excepto su viejo perro, que lo saluda y muere de alegría entre sus piojos. ¿No es acaso la muerte de un perro sarnoso en un estercolero el colmo mismo de la inmundicia? No. El último gesto de Argos es un gesto de generosa y abnegada nobleza, y sigue siendo una figura heroica en nuestros corazones" 13 .

Un elemento fundamental del mito uliseano esel dela ausencia involuntaria dela patria y del hogar. Realidad vivida por los miles y miles de desterrados y exiliados de que está poblada la historia humana. En todas las latitudes y en todas las épocas ha habido seres humanos lanzadoslejos dela tierra natal y del hogar. En Occidente, desde la Antigüedad griega hasta el siglo XX de las grandes guerras y las terribles tiranías. Pensamos en Grecia y nos vienela imagen de Temístocles y de tantos otros. Pensamos en Roma y evocamos a Ovidio, el tan grande y tan desdichado poeta. Pasamos a la Edad M edia y nos embarga el dolor de Dante, dejando sus cansados pies en escalas extranjeras. Y cuántos y cuántos. Joachim Du Bellay, desterrado en Italia, recuerda como felices en su bello soneto a aquellos que hicieron el viaje de Ulises y pudieron volver a la patria:

${ }^{12 E}$ I "Ulises" de Tennyson, en traducción de O scar G. Ramos puede verse en la citada obra de éste La O disea: in itinerario humano, pp. 169-171.

${ }^{13} \mathrm{G}$. Highet, La tradición clásica. Influencias griegas y romanas en la literatura occidental. Trad. A. Latorre, ${ }^{3^{a}}$ reimpr., F. C. E., M éxico, 1996, vol. II, p. 319. 
¡Dichoso el que, como Ulises, hizo un bello viaje, y después regreso lleno de experiencia y sabiduría a vivir entre los suyos el resto de su edad!14

Y llegamosa nuestra atormentada América con sus dictaduras. Para cuántos, el tema de la nostalgia, del nostos, del regreso a la tierra patria, y del algos, el dolor por la imposibilidad de volver, pasó de ser un tema del mito y dela poesía a ser una vivencia dolorosa y angustiante. Cuántos en esa lejanía forzada e insuperable por tantos años, aprendimos a releer y a amar más la 0 disea. Porque precisamente, el dolor que causa la lejanía forzada de la tierra natal y la imposibilidad de retornar a ella o los grandes obstácul os quese oponen a ese retorno, es el sentimiento expresado en la historia de Ulises y en las lágrimas que tantas veces derrama éste al recordar su hogar.

$\mathrm{H}$ ay también otro aspecto del exilio, el conocimiento de nuevos paisajes humanos y geográficos, que está reflejado en el mito de Odiseo. El regresa cargado de experiencias y conocimientos, vuelvecambiado por ellos. Esta "técnica de conocimiento", sobre la que escribía Vintila H oria, esta dolorosa forma deadquirir nuevos conocimientos, es otra faceta de la terrible experiencia de la lejanía forzada. Por eso, recordando la expresión de Oscar Gerardo Ramos y asociando el destierro a los conocimientos que entrega, pudimos escribir unas páginas con este título: La O disea y el exilio: itinerarios del saber y del dolor ${ }^{15}$.

Volviendo a las preguntas quese formulan en la convocatoria a esteciclo, podemos decir que esa "inquebrantable autoridad" que ejercen los relatos míticos griegos en la imaginación del O ccidente, se explica quizás en el caso del mito uliseano por el hecho de que también los hombres de los tiempos modernos pueden verse reflejados en Ulises, en sus padecimientos y sus anhelos, en sus derrotas y sus victorias ${ }^{16}$. Hay otros personajes míticos que, aunque nos atraigan por sus trágicos destinos, están más alejados de nosotros: Fedra, Teseo, Proserpina, por ejemplo. El propio Aquiles está más lejos, el héroe que reúne en sí bellas cualidades, el personaje sobre quien escribió conmovedoras páginas Goethe en su Aquileida, el hombre que debe morir joven y que, si bien no puede eludir el sino, se preocupa de su gloria terrena y póstuma.

Es notable el hecho de que las dos grandes obras literarias que en el siglo XX toman la figura de $O$ diseo, el U lises de J oyce y la O disea de Kazantzakis,

${ }^{14}$ Es el Soneto XXXI de sus Regrets: Heureux qui, comme U lysse, a fait un bon voyage...

${ }^{15}$ Publicado en el Boletín de la Academia Chilena de la Lengua $\mathrm{N}$ 0 71, 1993-94, se editó como separata, Santiago, 2000 y za ed., 2002.

${ }^{16} \mathrm{M}$ uy interesantes sugerencias acerca de la atracción que produce el tema de U lises entrega Jacqueline de Romilly en el ensayo “:Por quéO diseo?", en Rencontres avec la GrèceAntique, Trad. al griego K. Miliaresi y B. Athanasíu, Atenas, Ed. To Asti, pp. 67-89. 
pudieron establecer, respectivamente, un paralelo con el personaje y su peregrinar y una continuación vastísima de su viaje. En Joyce, el paralelo de Odiseo pudo ser un hombre común y corriente de la ciudad de Dublín, a comienzos del siglo XX. Leopoldo Bloom es un dublinés medio, como tantos otros habitantes de la ciudad irlandesa. En Kazantzakis, esel propio Ulises el que inicia una nueva travesía a través de mares, continentes y épocas. Y aunque esto parece contrario a la esencia del mito del regreso, reconocemos en el personaje al viejo marino. El ha llegado a su isla; ha castigado a los pretendientes; ha impuesto el orden; narra en síntesis sus peripecias a su familia, como lo hizo antes in extenso frente a los feacios; sepulta con los ritos tradicionales a su padre Laertes; casa a su hijo Telémaco; reúne a algunos aventureros y se lanza de nuevo al mar. Antes, ha experimentado, con lágrimas, la emoción de contemplar desde una colina a su isla humilde que durante tantos años anheló volver a ver; visitó a los antepasados que dormían en perpetua quietud en sus tumbas, en un viejo jardín. Pero el afán de conocer todavía más hombres y más tierras - que confiesa en los versos de Dante- y la sensación de estrechez que siente en su hogar y entre sus súbditos acomodados en el egoísmo y la rutina - de que habla en el poema de Tennyson-, son cada día más fuertes. Y en palabras del poeta Kavafis, "Io venció la nostalgia / de los viajes y de las llegadas / matinales a los puertos donde, / con qué alegría, entras por primera vez"17.

¿En busca de qué va ahora Ulises? ¿Cuál es su nueva Itaca? Ni él mismo lo sabe al partir. Toda la gigantesca O disea de Kazantzakis es, como la homérica, una búsqueda. Algunos han dicho una búsqueda de Dios, si éste existiera. Otros han visto la interminabletravesía como la búsqueda del sentido que pudiera tener el caos que son el hombre y el mundo.

Decíamos que a pesar de que la utilización del mito uliseano por Kazantzakis parte de su inversión, reconocemos en todo momento al antiguo $O$ diseo. Son muchas las ocasiones en que, en medio de tantas y a veces casi inverosímiles nuevas peripecias, vuelven los recuerdos de su homérico viaje: en la memoria reaparecen Troya, I taca, el padre, la esposa, el hijo. Ulises sueña con su isla y sueña con su madre Anticlea. En Homero sólo vuelve a ver a su madre como una sombra en el mundo delosmuertos. En Kazantzakis sólo la vuelve a ver en un muy emocionante sueño. El perro Argos, a miles de años de su muerte, sale de su tumba para ir a acompañar a su amo en su agonía, en uno de los pasajes más hermosos del poema. La importante presencia de Helena en esta obra enlaza continuamente el tiempo actual del poema con el homérico. En ella y en $\mathrm{O}$ diseo se conectan dos mitos de gran simbolismo y degran humanidad.

${ }^{17}$ C. Kavafis: "Segunda O disea", 1994. Publicado en Castillo Didier, M .: Kavafisíntegro, Santiago, Centro de Estudios Griegos, Bizantinos y Neohelénicos, II vol., pp. 668-669. 
Un rasgo especial del mito de 0 diseo es el hecho de que éste puede precisamente ser calificado de "mitoclasta", de destructor de mitos. Ulises es el hombre que lucha contra poderes irracionales, suprahumanos. Debe batirse con dioses hostiles, con monstruos hostiles, con hombres hostiles. Debe luchar sin tregua hasta salir de las redes de lo fantástico, de lo caótico, de lo antihumano, de lo irracional. Oscar Gerardo Ramos, al reencontrarsecon la 0 di sea y sus personajes, mientras realizaba un periplo por los sitiosarqueológicos griegos, empezando por M icenas, escribió: "Vi en Odiseo al mitoclasta, al instaurador de la razón, al expedicionario de los sentimientos, que busca la verdad de la existencia; al esposo y al padre que, lejos del hogar, comprende su destino como hombre; al príncipe que se acendra de experiencias para reencontrar la patria" ${ }^{18}$. Kazantzakis ha acentuado el carácter de mitoclasta de personaje antiguo.

Se pueden aplicar a la historia de Ulises las palabras de Ernst Cassirer, para quien el mito "posee un valor gnoseológico muy amplio y, lejos de significar un oscurecimiento de la mente, contribuyó por el contrario a la creación de un verdadero humanismo y al control de los elementos del inconsciente" 19 .

Q uizás lo más representativo de este avance hacia la racionalidad y el humanismo, es el hecho de que Ulises rechaza la posibilidad de llegar a ser un inmortal y liberarse así de la muerte y de los sufrimientos que marcan la existencia del hombre. O diseo se afirma en su ser de hombre, a sabiendas de que la finitud es el inexorable destino del ser humano, destino que es siempre incierto, salvo en cuanto al fin, que de todos modos llegará. Pareciera que esta actitud deno aceptar la inmortalidad, que debió asombrar a Calipso y al propio Zeus, pudiera corresponder al rechazo de la tendencia de los humanos a forjarse dioses a su imagen y semejanza y de crearse esperanzas de una vida ultraterrena, como medio de compensar las incertidumbres y las penalidades de la existencia.

En la misma línea de avance hacia la afirmación de lo racional y lo humano está el rechazo a ser rebajado a la esfera animal, como consecuencia de la entrega al placer en el lecho de la maga Circe.

Así, pues, Odiseo se afirma en su calidad deser humano. No quiere ser ni dios ni animal. Quiere ser ni más ni menos que un hombre.

Otro poeta, Yorgos Seferis, desterrado para siempre cuando lo que hoy Ilamamos "limpieza étnica" acabó con su Esmirna griega natal en 1922, ha destacado ese carácter profundamente humano del personaje de este mito:

${ }^{18}$ O. G. Ramos, op. cit., p. 5.

${ }^{19}$ Ernst Cassirer: "El pensamiento mítico", en Filosofía de las formas simbólicas, FEC, 1972, cit. por José C. Bermejo: Introducción a la sociología del mito griego, cit., p. 38. 
A veces estoy cercado por el destierro...

Y se presenta delante demí, denuevo y otra vez, la figura de O diseo, con ojos enrojecidos por la sal del agua

Y por el deseo de volver a ver el humo que brota de la tibieza de su casa y su perro que envejeció esperando en la puerta.

Extiende la palma de una mano encallecida por las cuerdas y el timón, con una piel deteriorada por el bóreas seco, por el calor ardiente y la nieve.

Diríase que quiere expulsar al Cíclope superhumano que ve con un ojo, las Sirenas que cuando las oyes olvidas, a Escila y a Caribdis de entre nosotros: Tantos monstruos complicados, queno nos dejan pensar queera también él un hombre, que luchó en el mundo con el alma y con el cuerpo ${ }^{20}$.

Quizás, pues, la explicación de este retorno de los mitos griegos en la literatura occidental esté en el hecho de que ellos más que model o sean espejos de conducta y sentimientos humanos. Al menos en el caso del mito de Odiseo pareciera ser así. U lises busca, lucha, sufre, porque ama, como el ser humano busca, lucha, sufre, porque ama.

Con razón, Borges ha recordado en estos versos el amor de O diseo y las lágrimas que a aquél se asocian:

Cuentan que Ulises, harto de prodigios, lloró de amor al divisar su Itaca verde y humilde².

\section{REFERENCIAS}

Bermejo, JoséCarlos. 1994. Introducción a la sociología del mito griego. M adrid, Akal, p. 136.

Bermejo, José Carlos et al. 1996. Los orígenes de la mitología griega. Madrid, Akal, cit., p. 279.

Borges, Jorge Luis. 2002. Jorge Luis Borges: Los senderos de Itaca Grecia en la poesía de Borges. Traducción Nina Angelidis. Atenas, Instituto Cervantes.

Cassirer, Ernst. 1972. Filosofía de las formas simbólicas, "El pensamiento mítico". M éxico, F. E. C.

Castillo Didier, Miguel. 1975. “El tiempo, la muerte y la palabra en la O disea de Kazantzakis", Byzantion Nea Hellás, 3-4, pp. 243-246.

${ }^{20}$ Traducción completa de este poema en Seferis, Yorgos: M ithistórima, Stratis el marino, otros poemas, Introducción, traducción y notas M. Castillo Didier, Centro de Estudios Griegos, Bizantinos y Neohelénicos, Santiago, 2000.

21"Arte poética”, en J. L. Borges, Los senderos de Itaca. Traducción Nina Angelidis. Atenas, Instituto Cervantes, 2002, p. 18. 
Castillo Didier, M iguel. 1993-94. "La O disea y el exilio: itinerarios del saber y del dolor", Boletín dela Academia Chilena de la Lengua № 71, Santiago.

Castillo Didier, M iguel. 2000-2002. "La O disea y el exilio: itinerarios del saber y del dolor", Separata Boletín de la Academia Chilena de la Lengua, Santiago.

Choza, Jacinto y Choza, Pilar. 1996. Ulises, un arquetipo de la existencia humana, Barcelona, Ariel.

Dante, Alighieri. 1943. Divina Comedia, "Infierno", Canto XXVI, v. 94 y s. Buenos Aires. Instituto de Estudios I talianos.

De Romilly, Jacqueline. 1997. “'Por qué Odiseo?”, en Rencontres avec la Grèce Antique. Trad. al griego K. M iliaresi y B. Athanasíu, Atenas, Ed. To Asti, pp. 67-89.

Highet, G. 1996. La tradición clásica. Influencias griegas y romanas en la literatura occidental. Trad. A. Latorre, 3a reimpr., M éxico, F. C. E., vol. II, p. 319.

Kavafis, Constantino. 1994. "Segunda Odisea”, en Castillo Didier, M . Kavafisíntegro, Santiago, Centro de Estudios Griegos, Bizantinos y Neohelénicos, II vol., pp. 668-669.

Lasso de la Vega, José S. 1983. "Ulises y su mundo de ideales éticos", en "Etica homérica", Adrados, R. y otros (L. Gil Ed.): Introducción a Homero, Madrid, Ediciones Guadarrama, p. 315.

Llosa, Jorge G. 1965. El libro de O diseo, Santiago, Zig-Zag, p. 19.

Ramos, O. G. 1970. La O disea: un itinerario humano, Bogotá, Instituto Caro y Cuervo.

Reboreda, S. 1996. "Odiseo, el héroe peculiar", en Bermejo J. C., González R. J. y Reboreda S.: Los orígenes de la mitología griega, M adrid, Akal, p. 332.

Seferis, Yorgos. 2000. M ithistórima, Stratis el marino, otros poemas. Introducción, traducción y notas M . Castillo Didier, Santiago, Centro de Estudios Griegos, Bizantinos y Neohelénicos.

Tennyson, Alfred. 1970. “Ulises”, en La O disea: un itinerario humano. Oscar G. Ramos (traduc.), pp. 169-171. 
